\section{Commentary: The enigma of surgery to cure thymic paraneoplastic syndromes}

\author{
Nirmal K. Veeramachaneni, MD
}

Blalock and colleagues ${ }^{1}$ began their 1939 landmark article on myasthenia gravis and tumors of the thymic region by quoting James Ewing: "No group of tumors has more successfully resisted attempts at interpretation and classification than those of the thymus." In 1936, Blalock removed a thymic tumor in a 21 year-old woman who had a history of episodic exacerbations of myasthenia gravis. After the operation, she had improvement in her neurologic symptoms and required less medication. Interestingly, the patient was treated multiple times with radiation before the operation. This remarkable operation was undertaken because "it seemed possible that removal of the tumor might result in improvement, and because the risk inherent in the operative procedure was judged to be not great." Ironically, by 1939 , only 4 cases of thymectomy to treat myasthenia gravis (in the setting of an associated thymoma) were known to Blalock and colleagues. These operations were performed by Sauerbruch, with 2 of the patients dying of subsequent mediastinitis and the remaining 2 patients, who survived the operation, noted to have improvement in their symptoms. ${ }^{1}$ The concept of thymectomy for myasthenia gravis was soon extended by Blalock to patients without thymoma. The rationale for this leap of logic remains unclear. ${ }^{2}$ In a 2-month period, weeks after joining Johns Hopkins University, Blalock proceeded to operate on 6 patients, with 1 death and improvement in the remaining patients. ${ }^{3}$ Among his first 20 patients, 4 died, 3 had no improvement, and 3 were described as essentially well with no need for prostigmine, a drug only identified and introduced into practice in the 1930s. ${ }^{4}$ Blalock was able to observe that the shorter the

\footnotetext{
From the Department of Cardiovascular and Thoracic Surgery, University of Kansas Health System, Kansas City, Kan.

Disclosures: Author has nothing to disclose with regard to commercial support.

Received for publication Nov 16, 2019; accepted for publication Nov 18, 2019; available ahead of print Dec 9, 2019.

Address for reprints: Nirmal K. Veeramachaneni, MD, Department of Cardiovascular and Thoracic Surgery, University of Kansas Health System, 4000 Cambridge St,

Kansas City, KS 66160 (E-mail: nveeramachaneni@kumc.edu).

J Thorac Cardiovasc Surg 2020;160:315-6

$0022-5223 / \$ 36.00$

Copyright (C) 2019 by The American Association for Thoracic Surgery

https://doi.org/10.1016/j.jtcvs.2019.11.088
}

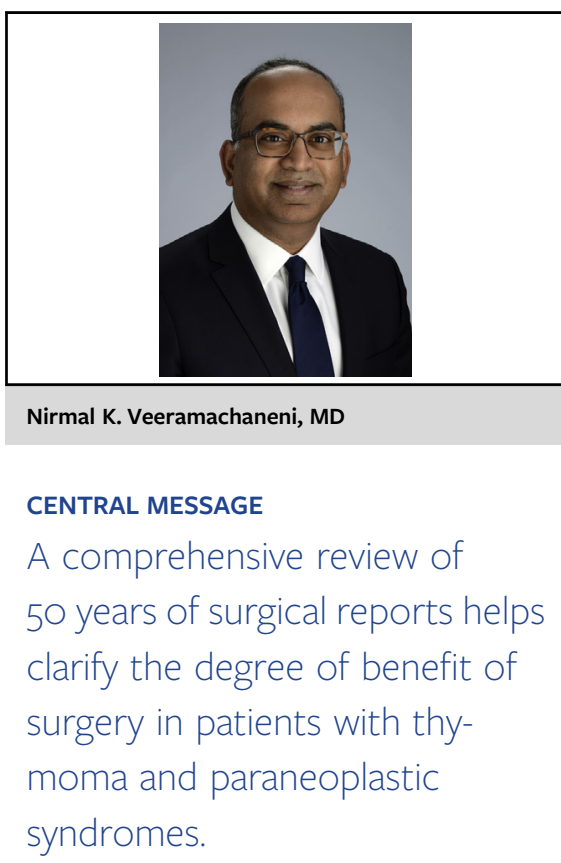

duration of symptoms preoperatively, the greater the chance of favorable response to the operation. ${ }^{4}$ The operation was applied with variable results, and the benefits have been interpreted with skepticism in subsequent decades. From the initial work of Sauerbruch, it took more than a century before we obtained randomized prospective data demonstrating the benefit of thymectomy in patients with myasthenia gravis without thymoma, definitively establishing the role for surgery. ${ }^{5}$

In the spirit of Blalock, Zhao and colleagues ${ }^{6}$ present in this issue of the Journal a truly exhaustive review of a half century of reports on the topic of paraneoplastic syndromes in the setting of thymoma. Zhao and colleagues ${ }^{6}$ have reviewed more than 400 reports and summarized the surgical outcomes of more than 500 patients with this narrow inclusion criterion. In addition to myasthenia gravis, 123 paraneoplastic syndromes have been identified and associated with thymoma. Zhao and colleagues ${ }^{6}$ note that $76 \%$ of patients had improvement of paraneoplastic syndrome after thymectomy; unfortunately, however, $21 \%$ of this group have relapse occur. Patients with resolution of paraneoplastic syndrome had the best outcomes for long-term survival. Given the obscurity of some of these syndromes, we are unlikely ever to have quality data beyond the present article to guide therapy. Although surgery seems to have a role in the care of these patients, 
the immunologic basis of these paraneoplastic syndromes remains an enigma.

\section{References}

1. Blalock A, Mason MF, Morgan HJ, Riven SS. Myasthenia gravis and tumors of the thymic region: report of a case in which the tumor was removed. Ann Surg. 1939; 110:544-61.

2. Kirshner PA. Alfred Blalock and thymectomy for myasthenia gravis. Ann Thorac Surg. 1987;43:348-9.
3. Blalock A, Harvey AM, Ford FR, Lilienthal JL Jr. The treatment of myasthenia gravis by removal of the thymus gland: preliminary report. JAMA. 1941;117: 1529-33.

4. Blalock A. Thymectomy in the treatment of myasthenia gravis: report of twenty cases. J Thorac Surg. 1944;12:316-39.

5. Wolfe GI, Kaminski HJ, Aban IB, Minisman G, Kuo HC, Marx A, et al; MGTX Study Group. Randomized trial of thymectomy in myasthenia gravis. $N$ Engl J Med. 2016;375:511-22. Erratum in: N Engl J Med. 2017;376:2097.

6. Zhao J, Bhatnagar V, Ding L, Atay SM, David EA, McFadden PM, et al. A systemic review of paraneoplastic syndromes associated with thymoma: treatment modalities, recurrence, and outcomes in resected cases. J Thorac Cardiovasc Surg. 2020;160:306-14.e14.
See Article page 306.

\section{Commentary: Toward a better understanding of the natural history of surgically treated thymoma associated with paraneoplastic syndromes}

\author{
Antonios Sideris, MD, and James Huang, MD
}

Thymoma is a rare disorder, with an incidence of 0.15 cases per 100,000 person-years. ${ }^{1}$ Surgery is the mainstay treatment for resectable tumors, with chemotherapy and radiotherapy offered in the neoadjuvant and adjuvant settings under certain circumstances. ${ }^{2}$ Thymoma is associated with a host of autoimmune and nonautoimmune paraneoplastic syndromes (PNSs), the clinical implications of which have been studied mostly in the context of myasthenia gravis (MG). Notably, a randomized trial of surgical resection versus medical management alone for nonthymomatous MG demonstrated improved symptomatology and quality of life for complete thymectomy over medical management alone. ${ }^{3}$

In this issue of the Journal, Zhao and colleagues ${ }^{4}$ report the results of a systematic review of 407 published studies on paraneoplastic disorders in patients treated with surgery

From the Thoracic Service, Department of Surgery, Memorial Sloan Kettering Cancer Center, New York, NY.

Disclosures: Authors have nothing to disclose with regard to commercial support. Received for publication Dec 10, 2019; revisions received Dec 10, 2019; accepted for publication Dec 10, 2019; available ahead of print Jan 7, 2020.

Address for reprints: James Huang, MD, Memorial Sloan Kettering Cancer Center, 1275 York Ave, New York, NY 10065 (E-mail: huangj@mskcc.org).

J Thorac Cardiovasc Surg 2020;160:316-7

$0022-5223 / \$ 36.00$

Copyright (c) 2020 by The American Association for Thoracic Surgery

https://doi.org/10.1016/j.jtcvs.2019.12.059
Check for updates

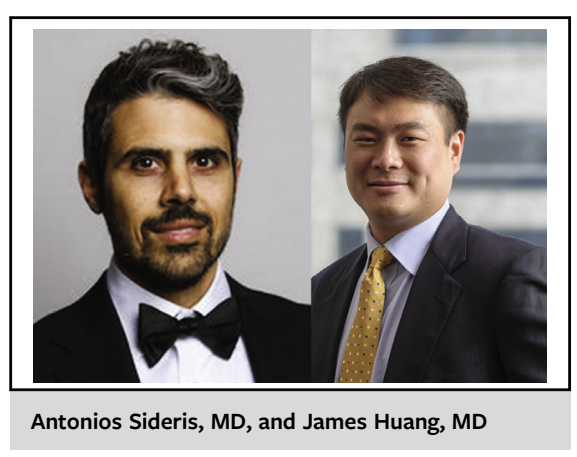

CENTRAL MESSAGE

Zhao et al provide an authorita-

tive cataloging of paraneoplastic

syndromes associated with sur-

gically treated thymomas. Ques-

tions on long-term outcomes for

syndromes other than myas-

thenia remain.

for thymoma between 1960 and 2019. They identified 507 patients, with a total of 123 distinct PNSs, which were present in $80 \%$ of patients before resection. Surgical resection led to remission or improvement of symptoms in $76 \%$ of patients. New onset of PNS was observed in $20 \%$ of previously asymptomatic patients, whereas recurrence of PNS occurred in $34 \%$ of patients, one third of whom had concurrent PNS and thymoma recurrence. A key finding was that complete resolution of PNS symptoms was associated with improved long-term survival.

This study is a noteworthy contribution to the literature. Compared with a recent study of PNSs in patients with thymoma from the International Thymic 